\title{
LA POLITTICA CONTRA EL CAPITAL. DE LA TEORÍA CLÁSICA DEL PLUSVALOR A LA LINGÜISTIFICACIÓN DE BORIS GROYS
}

\section{POLITICS AGAINST CAPITAL. FROM THE CLASSIC THEORY OF SURPLUS-VALUE TO THE LINGUISTIFICATION OF BORIS GROYS}

\author{
Angelo Narváez León \\ Universidad Católica Silva Henríquez, Chile \\ angelo.narvaezl@gmail.com
}

Recibido: febrero de 2021

Aceptado: mayo de 2021

Palabras clave: Marxismo, Plusvalor, Política, Lingüistificación, Marx Groys

Keywords: Marxismo, Surplus-value, Politics, Linguistification, Marx, Groys.

Resumen: En este artículo analizaremos uno de los múltiples recorridos de la crítica y de la política marxista, en la que se cruzan las interpretaciones de la teoría marxiana el plusvalor con la posibilidad de una derivación política de su lectura. Para ellos abordaremos tres grandes momentos de ese recorrido, desde la popularización de la lectura clásica del plusvalor, hacia el surgimiento de las lecturas divergentes dentro de los marcos comunes del marxismo para, finalmente analizar las hipótesis de Boris Groys sobre la subversión del orden lingüístico-representacional de la contradicción capital-trabajo.

Abstract: In this article we will analyze one of the multiple paths of Marxist criticism and politics, in which the interpretations of the Marxian theory of surplus value intersect with the possibility of a political derivation of its reading. For them, we will address three major moments of this journey, from the popularization of the classical reading of surplus value, to the emergence of divergent readings within the common frameworks of Marxism to, finally, analyze Boris Groys' hypotheses on the subversion of the linguistic orderrepresentation of the capital-labor contradiction.

\section{Introducción. Un recorrido posible del marxismo}

Hacia fines del siglo XIX, y a pesar de las reticencias de Marx, ya existía algo como un marxismo relativamente oficial, propiciado de una parte por la popularización engelsiana y, de otra, por las disputas dentro del Partido Socialdemócrata Alemán (PSdA) que encontraron en la figura de Marx un símbolo significante de legitimación (MEW XXXV: 
388; MEW XXXVII: 436). Sin embargo, a comienzos del siglo XX y tras la muerte de Engels, ese marxismo fundante comenzó a experimentar variaciones importantes tanto a nivel epistemológico como político: Ios trabajos de Hilferding, Bernstein y especialmente los de Kautsky, modificaron de manera sustancial el panorama de los debates marxistas en Europa. La llamada disputa por el revisionismo -der Revisionismusstreit (Papke, 1979; Melrose, 2016) - sostenida al interior del PSdA culminaría eventualmente con la escisión de los espartaquistas -Luxemburgo, Liebknecht, Zetkin- quienes tras la derrota de la revolución de 1919 fundarían el Partido Comunista Alemán. Ahora bien, y esto a pesar de sus diferencias, las posiciones en juego en esta disputa descansaron explícitamente en un desacuerdo político y estratégico del horizonte socialista y/o comunista a partir de interpretaciones de las funciones propias de la democracia y el proletariado en una revolución posible; pero también en disputas sobre la validez y representatividad de la teoría marxiana del valor y, por extensión, de la contradicción entre el mundo del capital y el mundo del trabajo. Aun cuando el mismo Marx veía con cierta afinidad la interpretación política que podría haber tenido El capital para el movimiento revolucionario en Rusia (MEW XXXV: 408), desconfiaba en ese mismo contexto de una traductibilidad directa entre la abstracción categorial y la organización social (MEW XXXV: 161).

Karl Kautsky por ejemplo, erigió parte importante de su interpretación política de la función histórica del PSdA explícitamente a partir del Nachlass marxiano que conformarían la edición de las Teorías de la plusvalía (1905-1910), publicado originalmente como el tomo IV de El capital. A su vez, ese mismo trabajo preparatorio le permitiría elaborar sus propias hipótesis sobre la actualidad de la crítica de la economía política en La cuestión agraria (Kautsky, 1968: 10). Lenin, por su parte, no tendría mayores problemas en asumir la representatividad histórica de las Teorías de Marx preparadas por Kautsky, en la medida que le permitirían realizar un análisis comparativo de la situación del campesinado en Rusia y Europa central, asumiendo subrepticiamente las Teorías como una ampliación de los márgenes de la teoría marxiana del valor más allá de la propuesta editorial popularizada por Engels con la cuarta edición alemana de El capital. Paradójicamente, asumir una posición de representatividad histórica no significó para Lenin la necesidad lógica de derivar las mismas conclusiones políticas propuestas por Kautsky: sobre esa misma base filológica Lenin incluso sostendría después sus críticas en La revolución proletaria y el renegado Kautsky, donde propondrá la dictadura del proletariado como "la esencia de la doctrina de Marx", desde donde la apuesta de Kautsky por la democracia parlamentaria suponía, por contraparte, un "olvido de la lucha de clases" (Lenin, 1972: 6). El debate Lenin-Kautsky, como antecedente, daría en algún grado la pauta de comportamiento a las primeras generaciones del marxismo occidental de los debates relativos a la posibilidad de derivación política de una interpretación particular de la teoría marxiana del valor.

Incluso ya alejados histórica y políticamente de los debates de la II Internacional, las generaciones posteriores del marxismo occidental replicaron el debate epistemológico inaugurado por el debate Kautsky-Lenin que situó la posibilidad de una ampliación de la teoría política del marxismo a partir de una revisión de los materiales filológicos del largo recorrido 
de la teoría marxiana del valor. Las publicaciones de los Manuscritos económicofilosóficos, de los Grundrisse, del capítuIo IV (inédito) de El capital-de especial importancia para el marxismo latinoamericano- $y$, posteriormente, de la MEGA ${ }^{2}$ (Musto, 2020), modificarían cada uno a su propio ritmo y modo el debate inaugurado en la II Internacional: a saber, cómo leer políticamente la crítica marxiana de la economía política. Una pregunta que el mismo Marx se realizaba, especialmente en los años inmediatamente posteriores a la publicación de El capital (MEW XXXII: 34, 211, 303). ${ }^{1}$

A pesar de la ansiedad de Marx, no podría decirse que entre 1867 y 1883 El capital haya carecido de una respetable recepción en Europa. La primera edición de mil ejemplares se agotó en poco más de un año, y a ese primer tiraje le siguió una reimpresión facsimilar que también se agotaría al poco tiempo (Tarcus, 2018). Para la muerte de Marx existían traducciones al ruso (Resis, 1970) y al francés (Anderson, 1983), y ya había noticias de proyectos de traducción al polaco y al danés (Miskewitsch, 1989; Blit, 1971; Callesen, 1989). Los países del Este, como las actuales Hungría o Rumania, leyeron El capital en el original alemán producto de la influencia lingüística directa o indirecta del Imperio Austro-Húngaro; en los casos de las actuales repúblicas post-soviéticas, enfrentaron la crítica marxiana de la economía política a través de las traducciones rusa y polaca. En términos generales,

1. Si bien la divulgación de El capital estuvo especialmente a cargo de las recensiones escritas por Engels, las críticas de Dühring, Rösler y Strasburger contribuyeron a visibilizar la crítica marxiana de la economía política más allá de los espacios asociados directamente a la socialdemocracia alemana (Siemes, 1962: 366). hacía el último cuarto del siglo XIX, Europa tenía ya una relación más o menos explícita con El capital; exceptuando, claro está, países como Italia, España o Portugal que, ante diferencias lingüísticas algo mayores, leyeron El capital a través de resúmenes de divulgación como el de Carlo Cafiero, traducciones del resumen francés de Gabriel Deville (Tarcus, 2017) o del resumen alemán de Johann Most (Haker, 2003: 20). Este contexto, sin embargo, no es puramente decorativo.

Hacia fines del siglo XIX, ya existía a nivel europeo y latinoamericano una disputa abierta entre marxistas y anarquistas por el sentido del socialismo y el comunismo como horizontes de transformación de la realidad. Esta disputa, heredera del quiebre de la I Internacional (1864-1876), supuso un enorme esfuerzo teórico, pero no por eso menos estratégico y político, por posicionar conceptualizaciones específicas del capitalismo como ejes interpretativos reales para la comprensión de las condiciones inmediatas de producción y reproducción de las masas trabajadoras. Entre muchas otras dimensiones, una de las apuestas más importantes del naciente marxismo estribó en la popularización de la crítica marxiana de la economía política en abierta oposición a una supuesta carencia de conceptualización crítica de las determinaciones materiales de la realidad por parte de las organizaciones anarquistas (Price, 2013: 35).

La popularización del marxismo requería, por tanto, un mecanismo tan inmediato y comprensible como las propuestas organizacionales anarquistas. Ese mecanismo estuvo desde un comienzo asociado a la pedagogización de la crítica de la economía política: ahora bien, si acaso esa pedagogización implicó simplificación y vulgarización, es un debate a nuestro parecer 
propio de la institucionalización disciplinar del marxismo y no de la apuesta estratégica a corto y mediano plazo del marxismo de fines del siglo XIX y comienzos del siglo $X X$. La eficacia y eficiencia de la estrategia mostró sus réditos casi inmediatamente con el vuelco marxista -forzado o no- de prácticamente la totalidad de los partidos socialistas y comunistas hacia el primer cuarto del siglo XX: vuelco propiciado, además, por la bolchevización y posterior sovietización de la Revolución rusa y su espectacular campo de influencia internacional. Desde la perspectiva la primera y segunda generación del marxismo occidental (Anderson, 2011), lo que los marxistas tenían, y de lo que sus opositores carecían, era una teoría científica del valor.

\section{La interpretación clásica de la teoría del valor}

La conceptualización marxista clásica de la contradicción capital-trabajo, que no necesariamente pretende resolver el antagonismo pero sí explicarlo y, en un grado no menor establecer con claridad la materialización concreta de esa contradicción, se sostiene sobre la base de la producción social del valor a través del trabajo productivo. Esta hipótesis podría sintetizarse metodológicamente de la siguiente manera: el capitalista detenta inicialmente los medios mínimos necesarios para la producción (mp), los cuales invierte de manera inmediata como un capital constante (cc) en un escenario abstracto en un proceso productivo específico; este $\mathrm{cc}$, sin embargo, no produce por sí mis$\mathrm{mo}$, sino que requiere de la fuerza de trabajo (ft) necesaria para poner en marcha los instrumentos y la transformación de la materia; este segundo aspecto del proce- so productivo aparece al capitalista como un capital variable (cv)². La contradicción aquí estriba en que en una jornada laboral de tiempo dado (t), el capitalista compra ft a través del salario; sin embargo, esa misma ft produce en un tiempo fragmentario de la totalidad de $t$ los elementos de su propia subsistencia. En el esquema propuesto más abajo (cfr. fig. $n^{\circ} 2$ ), eso significa que la ft produce su propio salario en el fragmento $a-b$, entregando toda la valorización del cc en el periodo b-c directamente al capitalista. Esa valorización de cc constituye, en términos generales, el plusvalor. Este plusvalor, forma excedente del plustrabajo realizado por el trabajador en el periodo b-c, se incrementa en términos absolutos ( $p v-a)$ cuando aumenta la jornada laboral, es decir, cuando las horas de la relación b-c se extienden sobre la base de subsistencia a-b; y, se incrementa en términos relativos (pv-r) cuando la jornada laboral disminuye. Históricamente, concluiría Marx según las in-

2. En palabras de Marx: "El excedente del valor total del producto sobre la suma del valor de sus elementos constitutivos, es el excedente del capital valorizado por encima del valor que tenía el capital adelantado en un principio. Los medios de producción, por una parte, la fuerza de trabajo, por la otra, no son más que diversas formas de existencia adoptadas por el valor originario del capital al despojarse de su forma dineraria y transformarse en los factores del proceso laboral. La parte del capital, pues, que se transforma en medios de producción, esto es, en materia prima, materiales auxiliares y medios de trabajo, no modifica su magnitud de valor en el proceso de producción. Por eso la denomino parte constante del capital o, con más concisión, capital constante. Por el contrario, la parte del capital convertida en fuerza de trabajo cambia su valor en el proceso de producción. Reproduce su propio equivalente y un excedente por encima del mismo, el plusvalor, que a su vez puede variar, ser mayor o menor" (Marx, 2010: 252). 
terpretaciones clásicas del plusvalor, ${ }^{3}$ esta última forma de valorización relativa sucede a partir de revoluciones tecnológicas que vuelven más eficiente la función del $\mathrm{cv}$, a la vez que disminuye su presencia. Esta relación, a su vez, era perfectamente comprensible a partir de una hipótesis general sobre el comportamiento empírico de la contradicción:

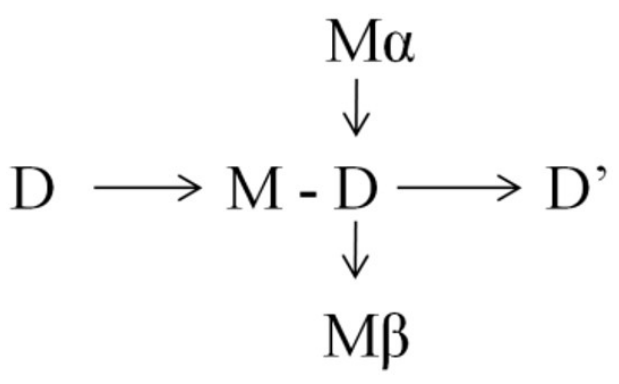

Figura $n^{\circ} 1$. Elaboración propia.

El capitalista detenta entonces una cantidad de dinero (D) con el cual compra una cantidad específica de mercancías (M); que, en este caso, es la suma del cc y cv dentro de un proceso productivo. La valorización que la ft-(cv) realizada desde y a partir de md-(cc) se retribuye al capitalista como dinero más ganancia (D'). Aquí, para el capitalista, D' es una ganancia absoluta en la medida que, insiste Marx, su inversión inicial en $\mathrm{M}$-cc se traspasa di-

3. Si bien los debates sobre el plusvalor como horizonte general de la crítica marxiana de la economía política excede por mucho estas páginas, cuando hablamos de una interpretación clásica de la teoría del valor incluimos -con sus variables y contradicciones- trabajos como los de Plejánov, Lenin, Franz Mehring, Rosa Luxemburgo, Lukács, etc., es decir, análisis que derivaron de una lectura de Marx una deducción del trabajador industrial como sujeto estratégico de la realidad. Para un panorama del debate (Fetscher, 1967; Ludz, 1972; Draper, 1977; Nimtz, 2014; Trawny, 2018). rectamente a D', a la vez que su inversión en M-cv valoriza ese traspaso que, a nivel amplio, se traduce en plusvalor. Desde la perspectiva del trabajador, sin embargo, la ft que detenta la oferta como mercancía (M $\alpha$ ) que transa por un salario (s) -que es equivalente a la inversión del capitalista en $\mathrm{M}-\mathrm{cv}$ regulada por el momento a-b-, el cual luego tranza nuevamente por mercancías de subsistencia (M $\beta)$. Esta es la razón por la cual M $\alpha$ no se transforma en $M \alpha$, pues desde la perspectiva del trabajador, la cuantificación de su salario (s), al depender del momento a-b, sólo se traduce en la reproducción de su ft, es decir en subsistencia inmediata. Sus mercancías a disposición no aumentan, sino que sólo se transforman (M $\beta$ ).

Desde esta perspectiva, el marxismo de fines del siglo XIX y comienzos del siglo XX, puso especial énfasis en esta dimensión gráfica (restricta: es decir, circunscrita al trabajo productivo directo) de la teoría marxiana del valor, pues permitía pedagógicamente explicar con bastante claridad la derivación política de la hipótesis general: los trabajadores producen valor en el sistema capitalista, por tanto los trabajadores son cualitativamente el sujeto estratégico de la transformación de la realidad.

Ahora bien, este esquema clásico de la producción de plusvalor absoluto y relativo, constituye en términos generales el paradigma a partir del cual se sustentaron análisis tan diferentes en su especificidad como los Rosa Luxemburgo y Henryk Grossmann (Carrique, 2019). El esquema, aparentemente nada más que abstracto, delimitó empíricamente posiciones políticas referentes a, por ejemplo, las disputas salariales socialmente circunscritas a fines del siglo XIX y comienzos del siglo $X X$ : ya que i) de una parte, se apostó por regular legalmente la relación 


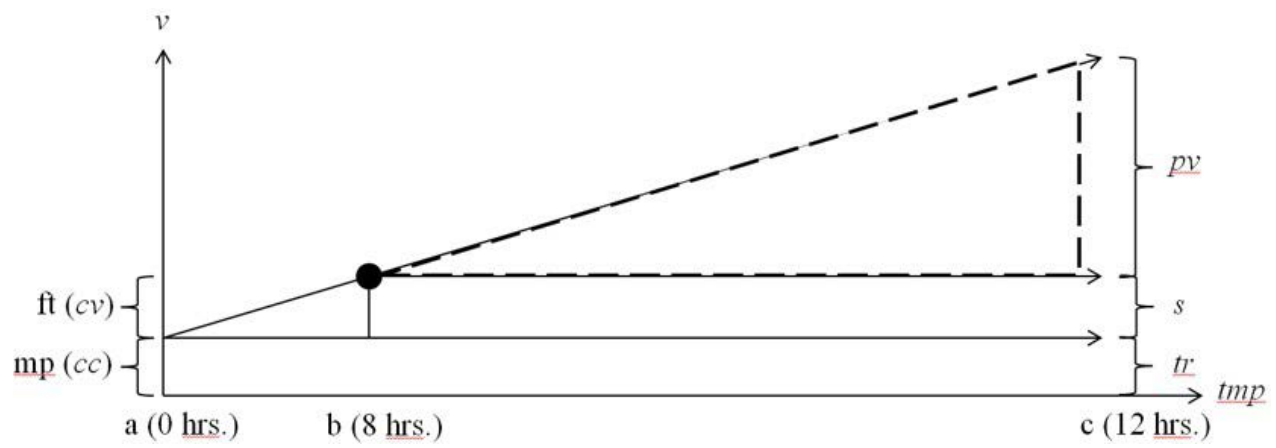

Figura $n^{\circ} 2$. Elaboración propia.

ab-bc, es decir, la jornada laboral, a la vez que se apostó por regular legalmente la transformación de $c v$ en $s$, es decir, ajustar nominalmente el salario asociado a esa jornada (esta es, dentro del contexto de la exposición histórica de El capital, la posición sistemáticamente trabaja por Marx en los capítulos XVII-XX); ii) de otra parte, se apostó por un aumento nominal del salario, pero reduciendo esta vez la jornada laboral, es decir, transfiriendo esa alza salarial desde una reducción del plusvalor absoluto y no sólo del plsuvalor relativo. Esta segunda posición que, dependiendo la perspectiva que se adopte puede parecer más o menos radical que la contención del plusvalor relativo, adquirió especial fuerza a comienzos del siglo XX en el contexto de transformación política y aumento de representatividad de la socialdemocracia alemana que derivaría, posteriormente, en el llamado estado de bienestar. Esta perspectiva restricta del valor, es la que fundamentó en definitiva la estrategia sostenida por Bernstein del socialismo como una administración positiva del capital en beneficio de los trabajadores mediante una reducción de las brechas salariales (Bernstein, 1982; 1990; 2018).

\section{Más allá de la teoría clásica del plusvalor}

El quiebre entre la socialdemocracia y el comunismo, entre muchas otros aspectos, encontró en el problema del salario un espacio especialmente representativo de sus posiciones políticas. Para el comunismo emergente, la posición socialdemócrata implicaba una reducción paulatina de la diferencia entre el plusvalor y el salario que, si bien palpable, podía proyectarse virtualmente al infinito sin representar necesariamente esa proyección una transformación cualitativa de una relación cuantitativa precedente. En términos políticos, esta crítica a la proyección +cuantitativamente infinita de la proyección diferencial de la contradicción capital/trabajo significaba que lo mejor que podía hacer la socialdemocracia era administrar eficientemente el capitalismo, sin por ello dar un paso cualitativo hacia el socialismo. Ese quiebre cualitativo es el que desde el horizonte comunista del siglo XX se dio a entender con el nombre de revolución: es decir, subvertir el orden hegemónico de la contradicción capital-trabajo de tal manera que, incluso existiendo aquí y allá el capital, éste estuviera subordinado 
a los intereses del mundo del trabajo y no de su propia producción y reproducción. Teóricamente, esto justificó los capitalismos de Estado, un escenario en el que el capital podía hipotéticamente existir nocapitalistamente en un horizonte de largo alcance de transformación comunista en que, eventualmente, la producción de bienes de subsistencia y goce podría realizarse a partir de una ganancia comercial sin tener necesariamente que subordinar esa ganancia a la producción de plusvalor. Este debate, entre socialdemócratas y comunistas, permeó prácticamente el sentido de todos los debates económicos de los ensayos históricos socialistas, de la Unión Soviética a Yugoslavia (Stambolieva, 2011; Kukić, 2015;) y Cuba.

Los debates sobre la posibilidad de una planificación descentralizada en Yugoslavia y los debates sobre la función del mercado y el dinero en Cuba -especialmente entre 1961 y 1965 (Fuentes de Armas, 2012; Pérez, 2008)- se presentaron explícitamente como propuestas políticas que no asumieron una posición administrativa del capital, sino una posición estratégica de proyección de subordinación del plusvalor al salario, del capital al trabajo: abriendo, a su vez, la discusión política hacia la cuestión de la existencia del capital en un mundo no-capitalista. Ambas posiciones precedentes (la reducción del pv-a o del pv-a/ pv-r -y sus consecuencias-), descansan sin embargo en una confianza en la política (constitucional o revolucionaria) como instancia de mediación entre los intereses del capital y los del trabajo: transformándose, incluso, en políticas de Estado. Es decir, transformando el debate de la crítica de la economía política en un debate sobre de la forma y función del Estado.

Lo interesante de este esquema en el contexto del siglo XX, es que en última instan- cia no sólo es válido para explicar diferentes posiciones dentro del marxismo, sino también más allá y a pesar del marxismo. Tanto el keynesianismo europeo (Mann, 2018) como la apuesta cepaliana latinoamericana (Ocampo, 2013) apostaron por una minimización del conflicto político del capitalismo estableciendo límites variables, pero más o menos precisos, al grado de diferencia que en el contexto de una economía nacional/regional podía tener el plusvalor (pv) por sobre el salario (s). La regulación del precio de las mercancías de subsistencia, por ejemplo, es una política que buscaba reducir la diferencia entre pv y s, pero sin modificar la relación ab/bc. Un mecanismo más sofisticado, pero a la postre derrotado a nivel latinoamericano por sobre todo, estribó ya no en reducir la brecha entre pv y s, sino en virtualmente desdibujarla transformando una parte del salario de los trabajadores en acciones y activos financieros (Gárate Chateau, 2012). Esta transferencia de activos, si bien reconoce paradójicamente el esquema marxista tradicional del plusvalor, lo circunscribe eventualmente a los márgenes de beneficio de la reproducción del capital global.

Sin embargo, y volviendo sobre el argumento central, la popularización de esta interpretación restringida de la teoría marxiana del valor y, por tanto, de la contradicción capital-trabajo, identificó los procesos de proletarización y de subsunción del campesinado a las exigencias de la proletarización global como eje de su posible efectividad: de ahí que los marxistas latinoamericanos de la segunda mitad del siglo XX no se hayan sentido del todo incómodos con la Industrialización por Sustitución de Importaciones (ISI), modelo que al menos teóricamente les daba de facto la razón al suponer la necesidad 
de un proceso estructural de industrialización nacional y, por tanto, de proletarización de la población (Marini, 1969; Dos Santos, 1966; Bambirra, 1978). Sin embargo, el problema que enfrentó el marxismo aquí fue doble: i) de una parte, por qué teniendo a disposición un argumento perfectamente coherente y consistente (y que, incluso históricamente, parecía confirmarse cada vez más a nivel global), no se producía una transferencia, un traducción, desde el campo de la interpretación lógica al de la movilización política y, ii) de otra parte, qué hacer cuando esa misma coherencia y consistencia entraba en un pantanoso escenario de incertidumbre al transformarse radicalmente la morfología social del trabajo (y la división social del trabajo) a nivel mundial (Antunes, 2003). Ambos problemas, referidos a la interpretación del fetichismo de la mercancía (y la enajenación), y a los procesos de politización asociados al mundo del trabajo aparentemente disociado de ésta matriz del plusvalor, dieron la pauta a los debates políticos de la segunda mitad del siglo XX.

El Estado de bienestar o de compromiso adquirió una fuerza notable tras la II Guerra Mundial, aunque con formas diferentes a nivel global, y habiendo existido antes también. El New Deal de los Estados Unidos es irreductible al keynesianismo europeo, y a su vez ambos son irreductibles al desarrollismo latinoamericano. Sin embargo, estas tres formas estuvieron transidas por una misma paradoja relativa a la derivación de una política a partir de una crítica de la economía política: i) de una parte, la tradición marxista (entre otras), vio en parte como un triunfo el establecimiento del Estado de bienestar, en la medida que históricamente respondería a una modificación del Estado a partir de los éxitos y logros de los movimientos obreros, campesinos y populares. La regulación del capital, las reformas agrarias y las propuestas de normalización de la vivienda, por ejemplo, canalizaron con fuerza esta posición; ii) de otra parte, la tradición liberal asumió el ascenso del Estado de bienestar y su política de compromisos y concesiones, como una estrategia explícita de contención de la influencias del mundo socialista (Mann, 2017).

Para el marxismo, este escenario se transformó en uno de sus mayores obstáculos, pues, siendo el Estado de bienestar un logro del movimiento obrero o una estrategia de contención, en ambos casos lo que se enfrentaba era una forclusión de la política socialista. Esto, en la medida que la condición de posibilidad de los acuerdos y compromisos descansaba en el reconocimiento de la democracia liberal como sistema de referencias para el debate público; y, si se aceptaba este sistema de referencias, en última instancia se estaba aceptando también el sistema de referencias del capitalismo. Así, lo mejor que podía ofrecer la democracia era contener cuantitativamente al capital, pero no subordinarlo cualitativamente al mundo del trabajo. De aquí que Alain Badiou sostenga que el Estado de bienestar sea una antesala liberal para la masificación global del capital-parlamentarismo como significante político y económico mundial tras la debacle de la Unión Soviética (Badiou, 2005: 11).

Desde la segunda mitad del siglo XX, entonces, el problema del fetichismo de la mercancía ya no se traducía en el problema gnoseológico e ideológico del paso de la enajenación a la conciencia; sino que en el problema del reconocimiento consciente de la enajenación y, por extensión, en el reconocimiento de distensión de una hipotética voluntad revolucionaria. Paradójicamente, la desconfianza de la teoría 
y la confianza en la voluntad se transformó en una absoluta desconfianza de la voluntad y en una reclusión consciente, casi de subsistencia, en la teoría. Para bien o para mal, la Escuela de Frankfurt, en prácticamente todas sus generaciones, fue la expresión de esta transformación que, atendiendo a lo anteriormente expuesto, tiene pleno sentido hayan tendido mano al psicoanálisis como insumo para (ni siquiera justificar, sino que al menos) entender esta nueva posición y correlación. En unos pocos años el horizonte "teológico" del marxismo pasó del perdónalos Señor, porque no saben lo que hacen, al perdónanos Señor, porque sabemos perfectamente 10 que hacemos (Žižek, 2005; 1998).

El capitalismo, en este periodo histórico, apostó por un aumento sistemático de la producción de plusvalor relativo a partir de una revolución tecnológica permanente. Esta apuesta mejoró de hecho el nivel de vida de los trabajadores, al menos dentro del centro del capitalismo global, volviendo inconsistente en términos empíricos la interpretación clásica de la contradicción capital-trabajo. Este escenario, a su vez, propició la confianza depositada por el marxismo occidental en las propuestas socialistas de las periferias del capitalismo $y$, a la vez, en la posibilidad de un quiebre del capitalismo en sus centros a partir, ya no de los pauperizados, sino de los desplazados. El marxismo comenzó a adecuar su discurso desde la crítica de la explotación a los márgenes de la exclusión, dominación y discriminación, paradójicamente, volviendo cada vez menos representativa la interpretación clásica y restricta de la contradicción capital-trabajo.

Ahora bien, el concepto de periferia fue fundamental en la transformación del marxismo en la segunda mitad del siglo $\mathrm{XX}$, especialmente en los países del este europeo reticentes a la influencia soviética - particularmente Yugoslavia- y, por supuesto, en Latinoamérica, donde la dinámica centro-periferia fue conceptualizada con especial énfasis a partir de la noción de dependencia (Bambirra, 1978). En ambos casos, la dinámica centro-periferia supuso una lectura de la contradicción capital-trabajo a partir de la especificidad de los espacios nacionales y continentales que, por diversas razones, no respondían a las condiciones normales de desarrollo de los capitalismos centrales. Lo notable de estas posiciones estuvo en que esto significaba a la vez que el proyecto socialista soviético tampoco daba cuenta de la especificidad periférica en la medida que había logrado situar en el centro de la disputa por la transformación del capitalismo, derivando -por contradictorio que parezca en relación a la dependencia- en una posición de radical autonomía política de la periferia.

La autonomía, asociada a la especificidad de la dependencia de la periferia, se tradujo en una paulatina ampliación y conjugación de la teoría marxiana del valor más allá de sus límites restrictos, llegando a conceder validez y representatividad a tesis como las de Raúl Prebisch y Hans Singer (Ocampo, 2003) o a las de Albert 0. Hirschman (1963) y Franz Hinkelammert (1970), bastante alejadas del núcleo analítico tradicional del marxismo. El escenario político de la periferia produjo algo más que suspicacias de parte de la Unión Soviética, lo que se tradujo en una reducción variable de las confianzas (incluido el financiamiento) hacia los partidos comunistas, y en una negación de cualquier viabilidad de los proyectos políticos de las organizaciones no alineadas a la III Internacional.

Paralelamente la Unión Soviética ya había recorrido un largo camino de deslegitimación. Las purgas estalinistas (1933) y el 
pacto Mólotov-Ribbentrop (1939) habían provocado el quiebre de los partidos comunistas europeos -especialmente el francés-; los procesos de des-estalinización de Kruschev (1962) no lograron modificar el escenario y, posteriormente, el vuelco propuesto por Brézhnev de una economía productiva hacia una economía de bienes de consumo (1964) constituiría un antecedente inmediato de las glasnost y la perestroika. Si bien hacia el gobierno de Brézhnev la Unión Soviética ya no contaba con prácticamente ningún apoyo real o simbólico a nivel internacional (exceptuando apoyo forzado de sus economías satelitales), el decurso posterior de la economía soviética implicó un vuelco también de sus principios económicos fundacionales: la interpretación restricta de la teoría marxiana del valor forzó, a decir de Theotônio dos Santos, la necesidad de subsistir capitalistamente ${ }^{4}$. De este modo, prácticamente todos los ensayos de interpretación restricta del plusvalor encontraron sus límites de una u otra manera.

4. Dice al respecto Dos Santos: "Los campesinos rusos habían sido obligados a pagar por la acumulación primitiva que permitía el desarrollo y la industrialización de las regiones más atrasadas de la URSS [...] Rusia no tenía el superávit imperialista que había enriquecido a Gran Bretaña y a la Europa occidental. Al contrario, se veía obligaba a pagar por el desarrollo de las regiones más atrasadas de la URSS, del Este europeo, de Cuba, de Vietnam y, más recientemente, de África y Afganistán [...] Por eso, en 1990 se dio esta extraña situación: un plebiscito para decidir el destino de la Unión Soviética mostró el centro del «imperio» votando por la disolución y la «periferia» votando por su conservación. Lo cual evidenciaba que la retórica rusa correspondía quizás a una realidad. El imperialismo soviético era contrario a los intereses del centro (Rusia). En cambio, una Rusia independiente, una relación con Estados nacionales «independientes» de la Unión Soviética podía quizás explotar esos países y ampliar sus bases de acumulación de capital" (Dos Santos, 2007: 306).

\section{La linguistificación del capital}

Desde la perspectiva propuesta por Robert Kurz, la implosión y debacle de la economía soviética no es tanto un argumento en favor del capitalismo como uno en favor, paradójicamente, del horizonte económico y político socialista (Kurz, 2002). La tesis de Kurz estriba en que el problema político y económico de la URSS radicó en que ensayó a partir de una política centralizada un ejercicio de distribución de la ganancia capitalista, asociada a los espectaculares índices productivos previos la crisis estacionaria estructural de fines de los 70' -una Modernisierungsdiktatur (Kurz, 2002: 227)-, sin por ellos subvertir realmente la subordinación y subsunción del trabajo al capital. Si bien la URSS intentó por múltiples medios evitar los procesos de acumulación, esa misma pretensión mostró la imposibilidad de funcionamiento a mediano y largo plazo de un capitalismo socializado sin acumulación. Las consecuencias de ese proyecto centralizado, con matices por supuesto, resulta análogo desde la perspectiva de Kurz a los ensayos latinoamericanos de mediados de siglo que derivaron en complejos escenario de estancamiento, inflación y depreciación. La paradoja aquí está en que la URSS hizo propios los principios productivos del capitalismo pretendiendo modificar los aspectos del consumo, los distributivos y acumulativos, volviendo ineficientes esos mismos principios dentro del contexto de competitividad global. Políticamente, la URSS fue el último gran intento por subordinar la economía (en todas sus dimensiones) a una política decisional centralizada, de modo que el fracaso de la URSS es tanto un fracaso económico como político. 
Esto significa un argumento en favor del socialismo en cuanto la crítica de Kurz reconoce perfectamente bien las consecuencias de la producción, consumo, distribución y acumulación capitalistas, a la vez que reconoce la imposibilidad de funcionamiento de la producción capitalista sin sus otras dimensiones estructurales: o, dicho de otro modo, el argumento de Kurz supone entender a la URSS como el ejercicio de un Estado político de bienestar llevado al extremo. El límite absoluto del capitalismo, ante el cual no hay salida, al menos desde esa misma perspectiva restricta.

Boris Groys, por su parte, y prácticamente a lo largo de toda su producción teórica, supone el argumento contrario en la medida que estima una valoración realmente comunista de la URSS como un ejercicio de subordinación de la economía a la política (Groys, 2006). Para Groys, la URSS es una experiencia comunista al determinar sus decisiones económicas (especialmente el consumo, la distribución y la pretensión de negación de la acumulación) desde el lenguaje político de todas las formas centralizadas (internacionales, nacionales y locales) del Partido Comunista de la Unión Soviética, por lo que no se puede decir "que la Unión Soviética fracasara económicamente, ya que el fracaso económico sólo es posible en el mercado. Y el mercado no existía en la Unión Soviética", de modo tal que "aquí ni el triunfo ni el fracaso económico de los liderazgos políticos podría establecerse «objetivamente», es decir, neutralmente, no-ideológicamente". Esta posición se tradujo, de acuerdo a Groys, en que:

"Ciertas mercancías eran producidas en la Unión Soviética no porque se vendieran bien en el mercado, sino porque formaban parte de una visión ideológica del futuro comunista. Y, por otra parte, aquellas mercan- cías que no podían ser legitimadas ideológicamente, no se producían. Esto era verdad para todas las mercancías, no sólo para los textos o imágenes de la propaganda oficial En el comunismo soviético toda mercancía se convirtió en una declaración ideológicamente relevante, tal como en el capitalismo toda declaración se convierte en una mercancía. Uno podía comer comunistamente, alojar o vestirse comunistamente -o también no-comunistamente, e incluso anti-comunistamente. Lo que significa que en la Unión Soviética, en teoría, así como era posible protestar contra los zapatos o los huevos o la salsa entonces disponible en tiendas, también era posible protestar contra las doctrinas oficiales del materialismo histórico. Podían ser criticadas en los mismos términos, porque esas doctrinas tenían el mismo origen que los zapatos, los huevos y las salsas, a saber: las decisiones relevantes del Politburó del Comité Central del Partido Comunista de la Unión Soviética. Todo en la existencia comunista era del modo que era porque alguien había dicho que de ese modo debía ser, y no de otro. $Y$ todo lo que se decide en el lenguaje puede de la misma manera criticarse lingüísticamente." (2006: 10)

Aquí la hipótesis (y el largo argumento) de Groys es relevante por dos razones: primero, porque subrepticiamente supone la inexistencia de la contradicción capital-trabajo en la estructura productiva de la Unión Soviética y, segundo, porque (no tan) implícitamente da a entender que podemos comprender el lenguaje como el medio y expresión de la política: "La pregunta de si acaso el comunismo es posible está entonces profundamente conectada con la pregunta de si acaso el gobierno, la organización y la administración política pueden realizarse en el lenguaje y a través del lenguaje" (Groys, 2006: 11). Es decir que, si para Groys el comunismo es el proyecto que subordina la economía a la política, entonces "la re- 
volución comunista es la transcripción de la sociedad desde el medio del dinero al medio del lenguaje. Es un giro lingüístico al nivel de la praxis social" (2006: 7). Desde la perspectiva de Groys es realmente posible ser comunista en la medida que la política y no la economía signifique la realidad. Por supuesto, eso no significa que el comunismo, como lingüistificación de la realidad, resuelva los procesos empíricos de subordinación de la economía a la política, pues "bajo las condiciones económicas capitalistas, la paradoja puede ser interpretada como un conflicto de intereses y puede resolverse, al menos provisionalmente, por un compromiso en los medios del dinero". Sin embargo, concluye Groys, "en los medios del lenguaje [...] la paradoja no puede pagarse ni, por consecuencia, disminuirse. Esto implica que si el comunismo se entiende como la traducción de la sociedad a los medios del lenguaje, entonces no promete una vida idílica, sino una vida en la autocontradicción, una situación de la mayor división y tensión internas" (2006: 60).

El problema, por cierto, con la hipótesis de Groys, no es sólo que no ofrece procedimientos de esa misma lingüistificación de la realidad (y que, claro, no tendría por qué pretender entregarlos); sino que, además, implica una confianza radical en la politización decisional de la realidad: lo que, paradójicamente, nos obliga a enfrentar nuevamente la crítica de Kurz. Este ir y venir entre las hipótesis de Kurz y Groys constituyen la gran paradoja de la palabra y la lingüistificación: la gran paradoja de una política socialista (y/o comunista) en el siglo XXI.

A pesar de sus diferencias, Kurz y Groys erigen sus interpretaciones de la Unión Soviética no con la finalidad de criticar o defender -respectivamente- su repre- sentatividad histórica; sino que en ambos casos la Unión Soviética representa un recurso metodológico para situar la discusión sobre la posible subordinación de la economía a la política en el horizonte de la transversalidad global (aunque diferencial) del neoliberalismo contemporáneo. Es decir, en el sentido de la posibilidad de una politización post-neoliberal.

En el neoliberalismo la contradicción capital-trabajo adquiere una forma particularmente específica (Harvey, 2014; Lazzarato, 2013). Si bien el capital financiero cumple una función determinante en la conceptualización marxiana de largo alcance de la teoría del valor en El capital (más allá de los márgenes de su exposición en el tomo I), la tradición del marxismo occidental -al menos hasta el último cuarto del siglo $X X$, momento en que ya se comenzaban a ver con claridad las dinámicas de los procesos de neoliberalización- tendió a representar el capital financiero a partir de los ritmos del capital productivo; a momentos, incluso, interpretándolo como un especie de resguardo ante los avances de la influencia del mundo del trabajo sobre el mundo del capital. Sin embargo, una vez hegemónico el neoliberalismo, especialmente tras el triunfo revanchista sobre el este europeo y el progresismo latinoamericano, el marxismo tendió a subvertir el orden de los factores atendiendo la lógica del capital productivo a partir de los ritmos del capital financiero.

Si retomamos la contradicción capitaltrabajo desde la perspectiva del salario, el escenario es especialmente claro. Hasta mediados del siglo XX la diferencia entre la variación ascendente o descendente (en escenarios de recesión) del salario formal o nominal en relación al salario real se contuvo a partir de políticas públicas 
y gubernamentales que, a momentos explícitamente, buscaron contener la posibilidad de estallidos sociales masivos. Las canastas familiares, el control aduanero, la subordinación de la banca al Estado, son ejemplos de la institucionalización de esta mediación centralizada entre los salarios formales y reales. Sin embargo, con el shock neoliberal y las políticas de monetarización, esta mediación se desplazó desde la política hacia el mercado (de los medios del lenguaje a los medios del dinero, en términos de Groys).

Esta transferencia implicó el vertiginoso avance y aumento de la representatividad de un tercer factor, el salario ficticio, en orden a satisfacer las necesidades de subsistencia, consumo y goce. Los derechos sociales asegurados en mayor o menor medida por el Estado (vivienda, salud, educación y jubilación, principalmente), atravesaron procesos estructurales de desposesión a nivel global (Harvey, 2007), transformándose rápidamente en bienes de consumo. Imposibilitados los salarios reales de satisfacer esas necesidades (en escenarios ya complejos de inflación para el valor de los salarios reales), el capital ficticio a través de la financiarización de la brecha salarial vino a subordinar económicamente esa diferencia entonces determinada políticamente. Si el capitalismo había logrado capitalizar el mercado a través del fordismo, el taylorismo, el toyotismo e, incluso, el keynesianismo, a lo largo del último cuarto del siglo XX logró mercantilizar de hecho al conjunto de la vida social a través de la neoliberalización. El carácter histórico del neoliberalismo es un problema que excede por mucho estas páginas; pero, si entendemos metodológicamente el capitalismo no como una base sobre la que se pueden adjetivar dinámicas específicas y diferenciales, sino como una di- námica que se realiza hegemónicamente a partir de la materialización de sus patrones de acumulación, entonces no es posible volver a un capitalismo pre-neoliberal.

Aquí la hipótesis de Slavoj Žižek sobre las transformaciones históricas es de especial interés. Si un cambio es realmente histórico, sostiene Žižek en su interpretación de Hegel, eso no significa que algo previamente existente al cambio histórico no pueda volver a suceder; muy por el contrario, significa que incluso a condición de suceder realmente, ya no significa lo mismo que en su estado precedente (Žižek, 2013: 193). Este argumento resulta imprescindible en la medida que permite tomar una posición crítica en relación a las propuestas post-neoliberales que se pretenden -tomando a Benjamin- depositarios del control sobre el freno de manos del decurso histórico del capitalismo. Es decir, como si la des-neoliberalización pudiese pensarse desde la perspectiva de un Estado de bienestar de acuerdos y concesiones ofertadas (por obligación política centralizada) del mundo del capital al mundo del trabajo.

Uno de los grandes ejercicios del neoliberalismo radica en transferir las coordenadas y referencias de la contradicción capital-trabajo desde el capital productivo al capital financiero; transferencia que en la práctica significa suprimir el horizonte político del capitalismo en virtud de su hipotética autonomía económica, a la vez que logra forzar a través de ese mismo desplazamiento un sentido común de subsistencia que reconoce perfectamente bien las reglas del mercado y de la mercantilización de la sociedad sin dejar espacio inmediatos claros a procesos diferentes de subjetivación. La gran astucia de los procesos de neoliberalización estriba entonces en suprimir lo que para el marxis- 
mo del siglo XX existía como condición de posibilidad de su realización: a saber, un mundo posible por fuera del mercado. Sin embargo, ese mismo mundo hoy se reproduce bajo las reglas de la neoliberalización y el sistema de referencias del capital-parlamentarismo.

\section{A modo de conclusión}

La gran dificultad a la que nos enfrenta el neoliberalismo estriba entonces en una negación sistemática de la efectividad y representatividad de los espacios y principios de utopía y esperanza, por seguir el lenguaje de Ernst Bloch (2007) y David Harvey (2003). Ahora bien, incluso antes de la crisis financiera de 2008-2009, parece cada vez más palpable la presencia de disputas (no solo debates y discusiones) en relación a la supervivencia (o no) del neoliberalismo como realización histórica del capitalismo: eso que Joseph Stiglitz -no precisamente un marxista- llamó el consenso del post-consenso de Washington (2004).

A pesar de sus diferencias imponderables, el consenso post-neoliberal no sólo carece de hegemonía a nivel global, sino que por lo demás es un consenso negativo en el sentido que establece un disenso sobre la pertinencia del neoliberalismo, pero no logra consensuar el sentido propositivo del disenso. Pero, si existe algún grado de acuerdo, éste radica en la necesidad de un regreso a la política y un retorno de la crítica de la economía política: es decir, desde nuestra perspectiva, en un retorno a Marx.

Sin embargo, una confianza en la transformación de la política -incluso en condiciones de subsunción económica y casi absoluta desventaja- sólo tiene sentido si se asume de entrada la posibilidad de una debacle catastrófica como resultado: es decir que, si se asume que puede haber tal cosa como un escenario post-neoliberal, ese escenario puede perfectamente resultar cuánto peor que el neoliberalismo contemporáneo. El espectro presencial de esa debacle implica una disputa intransigente relativa a cada significante de un horizonte post-neoliberal. O, leyendo ahora a contrapelo la hipótesis de Groys, significa confiar -al menos como apuesta- ya no (por ahora) en la traducción de la economía en política, del dinero en lenguaje; pero sí al menos en la traducción de una política administrativa en una política de proposiciones.

\section{Bibliografía}

Anderson, Perry (2011). Consideraciones sobre el marxismo occidental. Buenos Aires: Siglo XXI.

Antunes, Ricardo (2003). ¿Adiós al trabajo? Ensayo sobre la metamorfosis y el rol central del mundo del trabajo. Buenos Aires: Herramienta.

Badiou, Alain, (2005). El Siglo. Buenos Aires: Manantial.

Bambirra, Vanîa (1978). Teoría de la dependencia: una anticrítica. México: Era.

Bernstein, Eduard (1982). Las premisas del socialismo y las tareas de la socialdemocracia. Problemas del socialismo. El revisionismo en la socialdemocracia. México: Siglo XXI.

Bernstein, Eduard(1990). Socialismo democrático. Tecnos: Madrid.

Bernstein, Eduard (2018). Karl Marx y la reforma social. El socialismo democrático como fruto maduro del liberalismo. Barcelona: Página Indómita. 
Blit, Lucjan (1971). The origins of polish socialism. The history and ideas of the first socialist party. 1878-1886 Cambridge: Cambridge University Press.

Bloch, Ernst (2003). El principio esperanza. Madrid: Trotta.

Callesen, Gerd (1989). Zur Verbreitung der ersten dänischen Kapital-Ausgabe, Beiträge zur Marx-Engels-Forschung, 28, 75-80.

Carrique, Ángel (2019). "La acumulación del capital y el imperialismo: las posiciones de Rosa Luxemburgo comparadas con las de Henryk Grossmann", Revista Internacional de Pensamiento Político, 14, 41-64.

Dos Santos, Theotônio (2007). Del terror a la esperanza. Auge y caída del neoliberalismo. Caracas: Monte Ávila.

Dos Santos, Theotônio (1966). Crisis Económica y Crisis Política. Santiago de Chile: CESO.

Draper, Hal (1977). Karl Marx's Theory of Revolution. Vol. 1: State and Bureaucra$c y$. Londres: Monthly Review Press.

Gárate Chateau, Manuel (2013). La revolución capitalista en Chile. Santiago de Chile: UAH.

Groys, Boris (2006). Das kommunistische Postskriptum. Frankfurt am Main: Suhrkamp.

Fetscher, Iring (1967). Karl Marx und der Marxismus. Von der Philosophie des Proletariats zur proletarischen Welt. Múnich: Piper.

Fuentes de Armas, Rayza (2012). El pensamiento económico cubano durante el período 1960-1975. La Habana: Ediciones Universidad de La Habana.

Hacker, Rolf (2003). "Die Popularisierung des Das Kapitals duch Johann Most", conferencia ofrecida en Diciembre del
2003 en el marco del foro Johann Most (1846 - 1906) in Berlin. Vom Sozialdemokraten zum Sozialrevoluzionär.

Harvey, David (2014). Diecisiete contradicciones y el fin del capitalismo. Madrid: Traficantes de sueños.

Harvey, David (2007). Breve historia del neoliberalismo. Madrid: Akal.

Harvey, David (2003). Espacios de esperanza. Madrid: Akal.

Hinkelamert, Franz (1970). Ideologías del desarrollo y dialéctica de la historia. Santiago de Chile: Ediciones Universidad Católica de Chile.

Hirschman, Albert (1963). Journeys toward Progress: studies of economic policy-making in Latin America. Nueva York: Twentieth Century Fund.

Kautsky, Karl (1968). La cuestión agraria: estudio de las tendencias de la agricultura moderna y de la política agraria de la socialdemocracia. México: Siglo XXI.

Kukić, Leonard (2017). Regional Development Under Socialism: Evidence From Yugoslavia. Economic History Working Papers, 267, 1-55.

Kurz, Robert (2002). Schwartzbuch Kapitalismmus. Ein Abgesang auf die Marktwirtschaft. München: Ullstein Taschenbuchverlag.

Lazzarato, Maurizio (2013). La fábrica del hombre endeudado. Ensayo sobre la condición neoliberal. Buenos Aires: Amorrortu.

Lenin, Vladimir (1972). La revolución proletaria y el renegado Kautsky. Pekín: Ediciones en lenguas extranjeras.

Ludz, Peter Christian (1972). Soziologie und Marxismus in der Deutschen Demo- 
kratischen Republik. Múnich: Luchterhand.

Mann, Geoff (2017). In the long run we are all dead. Keynesianism, Political Economy, and Revolution. Londres: Verso.

Marini, Ruy Mauro (1969). Subdesarrollo y revolución. México: Siglo XXI.

Marx, Karl (2010). El capital. Crítica de la economía política. Madrid: Siglo XXI.

Marx, Karl (1956) [MEW]. Marx-Engels Werke. Berlín: Dietz Verlag.

Melrose, Jamie (2016). "Agents of knowledge: Marxist identity politics in the Revisionismusstreit", History of European Ideas, 42(8), 1069-1088.

Miskewitsch, Larissa (1989). Die russische Ausgabe des Kapitals von Karl Marx, Beiträge zur Marx-Engels-Forschung, 28, 115-124

Musto, Marcello (2020). "New Profiles of Karl Marx after the Marx-Engels-Gesamtausgabe (MEGA2)", Contemporary Sociology: A journal of Reviews, 49(5), 407-419.

Nimtz, August (2014). Lenin's Electoral Strategy from Marx and Engels through the Revolution of 1905: The Ballot, the Streetsor Both. EE.UU.: Palgrave Macmillan US.

Ocampo, José Antonio (2003). "Los términos de intercambio de los productos básicos en el siglo XX", Revista de la CEPAL, 79, 7-35.

Papcke, Sven (1979). Revisionismusstreit und die politische Theorie der Reform Fragen und Vergleiche. Suttugart: Verlag W. Kohlhammer.

Pérez, Omar (2008). "La estrategia económica cubana: medio siglo de socialismo", Cahiers des Amériques Latines, 5758(1-2), 31-55.
Price, Wayne (2013). The Value of Radical Theory. An Anarchist Introduction to Marx's Critique of Political Economy. Edinburgh: Ak Press.

Resis, Albert (1970). "Das Kapital Comes to Russia", Slavic Review, 29(2), 219-237.

Siemes, Johannes (1972). Karl Marx im Urteil des sozialen Rechts: Zur ersten wissenschaftlichen Rezensionvon Marx' Das Kapital, Der Staat, 11(3), 376-388

Stambolieva, Marija (2011). Welfare States in Transition 20 Years after the Yugoslav Welfare Model. Sofía: Friedrich Ebert Stiftung.

Stiglitz, Joseph (2004). "The Post Washington Consensus Consensus", conferencia presentada en Barcelona en el foro Initiative for Policy Dialogue: From the Washington Consensus towards a new Global Governance.

Tarcus, Horacio (2018). La biblia del proletariado. Traductores y editores de El Capital. Buenos Aires: Siglo XXI.

Tarcus, Horacio (2017). "Traductores y editores de la "Biblia del Proletariado". La suerte de El Capital en el mundo hispanoamericano, Revista Los trabajos y los días, 6 (7), 7-66.

Trawny, Peter (2018). Der frühe Marx und die Revolution. Eine Vorlesung. Frankfurt am Main: Vittorio Klostermann.

Žižek, Slavoj (2013). Less than Nothing. Hegel and the Shadow of Dialectical Materialism. Londres: Verso.

Žižek, Slavoj (2005). El sublime objeto de la ideología. Buenos Aires: Siglo XXI.

Žižek, Slavoj (1998). Porque no saben lo que hacen. El goce como factor político. Buenos Aires: Paidós. 